\title{
Prospective study of the functional outcome of uncemented bipolar hemiarhroplasty in displaced fracture neck of femur in elderly
}

\author{
Radhakrishna A. Mallegowda, Channappa T. Seetharam*, Shivanand Sundaram, \\ Jayaram B. Siddegowda, Veeresh Nijalingappa
}

Department of Orthopaedics, Kempegowda Institute of Medical Sciences, Bangalore, Karnataka, India

Received: 03 February 2020

Revised: 24 March 2020

Accepted: 31 March 2020

\section{*Correspondence:}

Dr. Channappa T. Seetharam,

E-mail: drchannappa@yahoo.co.in

Copyright: (C) the author(s), publisher and licensee Medip Academy. This is an open-access article distributed under the terms of the Creative Commons Attribution Non-Commercial License, which permits unrestricted non-commercial use, distribution, and reproduction in any medium, provided the original work is properly cited.

\section{ABSTRACT}

Background: Hip fractures in older patients are associated with impaired mobility, excess morbidity, mortality and loss of independence. To avoid the drawbacks of internal fixation and for early mobilization, hemiarthroplasty is performed in elderly. The bipolar prosthesis was developed to overcome the shortcomings of the unipolar fixed-head prosthesis. An additional site of motion would be expected to decrease the amount of loosening, dislocation, and head migration. The aim of the study is to assess the functional outcome of the patients with fracture neck of femur treated with bipolar hemiarthroplasty.

Methods: In this study, 20 patients above the age of 60 years with acute displaced fracture neck of femur underwent hemireplacement arthroplasty with bipolar prosthesis in Department of Orthopaedics, KIMS, Bangalore. The patients were followed up on 6 th, 12th, 18th, 24th week post operatively. Functional outcome was assessed with Harris hip score.

Results: In our study, mean average age was 72.3 years with predominantly female patients with $75 \%$ of the patients with left sided fracture. $95 \%$ of the patients had slight or no pain, $85 \%$ of patients had slight or no limp. $50 \%$ of the patients could walk without support, $65 \%$ of the patients could walk a distance of 6 blocks or more. Average Harris hip score was $82 \%$.

Conclusions: These results suggest functional outcome following bipolar hemiarthroplasty is good. Early mobilisation, pain free hip and with good level of activity is obtained following bipolar hemiarthroplasty.

Keywords: Fracture neck of femur, Bipolar prosthesis, Hemiarthroplasty, Harris hip score

\section{INTRODUCTION}

Hip fracture is a major public health problem. The incidence rises dramatically in the elderly population with osteoporosis. occurring in $87 \%$ to $96 \%$ of cases in people aged over 65 years. An estimated number of more than 6 million hip fracture is expected worldwide in $2050 .^{1}$

The treatment of displaced femoral neck fractures is based on the patient's age and activity level. Young active patients should undergo open reduction and internal fixation and older, less active patients are usually treated with hemiarthroplasty, either uncemented or cemented. Regardless of treatment method, the goal is to return the patient to his or her prefracture level of function. ${ }^{2}$

Hemiarthroplasty is associated with satisfactory functional recovery, early ambulation and a better clinical outcome compared to screw fixation. ${ }^{1}$ 
Development of bipolar hemiarthroplaty was based on clinical experience and complication experienced with unipolar prosthesis.

\section{Aims and objectives}

The aims were to study functional outcome in patient with fracture neck of femur treated with hemiarthroplasty with bipolar prosthesis, to facilitate early mobilisation, weight bearing and rapid rehabilitation after surgery, to avoid complication of internal fixation in elderly osteoporotic fracture like non-union, avascular necrosis, prolonged immobilisation and to study associated complication.

\section{METHODS}

The present study of 20 cases of intracapsular fracture neck of femur in elderly patient above the age 60 years treated by using hemireplacement arthroplasty with bipolar endoprosthesis in the Department of Orthopaedics at KIMS, Bangalore. Clearance has been taken by ethical committee.

The study was carried out to evaluate functional outcome of hemireplacement arthroplasty for fracture neck of femur using bipolar prosthesis.

\section{Inclusion criteria}

Patients with fracture neck of femur above the age of 60 years with all types of fracture under garden classification are considered. Only closed fracture is included.

\section{Exclusion criteria}

Patients aged less than 60 years of age with systemic and local infection excluded. All Compound fracture are excluded. Patients with neurovascular injury and pathological fracture are excluded.

In this study hemi replacement arthroplaty of hip is done in 20 cases of fracture neck of femur using bipolar prosthesis. Patients were followed up at an interval of 6 weeks, 12 weeks, 18 weeks, 24 weeks. Functional outcome was analysed by Harris hip scoring system. At each follow up radiograph of the hip was taken for radiological analysis.

An anterioposterior radiograph of the pelvis with bilateral hip is taken. Routine blood investigation, blood urea, serum creatinine, serology, ECG and 2D echo was done. Fitness for surgery was taken. Consent of the patient was taken.

\section{Surgical procedure}

All surgeries were performed on an elective basis using standard aseptic precautions under spinal or general anaesthesia. Patient was positioned laterally with posterior or southern - Moore approach
Technique curved incision was taken from $10 \mathrm{~cm}$ distal to the posterior superior iliac spine, extended distally and laterally, parallel with fibres of gluteus maximus muscle to the posterior margin of the greater trochanter. The incision was then directed distally $10 \mathrm{~cm}$ along the femoral shaft. By blunt dissection, the fibres of the gluteus maximus were separated taking care not to disturb the superior gluteal vessels in the proximal part of the exposure. The gluteus maximum muscle was split and short external rotators were exposed. A tenotomy of the short external rotators was done close to their insertion on the inner surface of the greater trochanter. The capsule was incised by a T-shaped incision. Using a head extractor and bone levers, head was delivered out of the acetabulum and the acetabulum was cleared of debris.

The fractured head and neck of the femur was levered out of the acetabulum and size measured using femoral head gauge. The size was confirmed using a trial prosthesis by its suction fit in the acetabulum. The acetabulum was prepared by excising remaining ligamentumteres and soft tissue. The femoral shaft was rasped using a broach (rasp) and prepared for the insertion of the prosthesis. Femoral neck if long was nibbled keeping 2 to $2.5 \mathrm{~cm}$ of calcar above the lesser trochanter

The appropriate-sized prosthesis was inserted into the reamed canal taking care to place it in $10-15^{\circ}$ of anteversion. Adequate seating of the prosthesis on the calcar was visualized directly. The reduction of the prosthesis was then done using gentle traction of the thigh. After suturing the capsule the external rotators were sutured, the wound was closed in layers over a suction drain,

\section{Post operative management}

IV fluids given and after 6 hours orals fluids are given after bowel movements reappeared.

Intravenous antibiotics and analgesics given and continued for 5 days postoperatively.

Abduction pillow is kept between lower limbs to prevent dislocation. Drain was removed at the first change of dressing after 48 hours. Check radiograph as done after 48 hours. Patients were made to sit up on the second day, stand up with support (walker), on the third day, and were allowed to full weight bear and walk with the help of a walker depending on his or her pain tolerance and were encouraged to walk thereafter. Sitting cross-legged and squatting were not allowed.

Suture removal was done on the 12 postoperative day. The patients were assessed for any shortening or deformities if any and discharged from the hospital.

Patients who had infection and bedsores were treated accordingly before discharging them from the hospital. 
Regular follow-up of all cases was done at 6 weeks, 12weeks, 18 weeks and 24 weeks. At each follow-up, patients were evaluated clinically using the Harris hip score and radiologically with appropriate X-rays. Harris hip score was used to evaluate the functional outcome in the present study.

\section{Harris hip scoring system}

Total functional outcome was graded as following depending on the total. Failure was Harris hip less than 60 , poor was Harris hip score between 60-69, fair was Harris hip score between 70-79, good was Harris hip score between $80-89$, excellent was Harris hip score between 90100.

Data collected was recorded and analysed using in MS Excel. The observations are presented in number and percentages.

\section{RESULTS}

There are 20 cases of fracture neck of femur above 60yr of age included in the study, at department of orthopaedics, KIMS, Bangalore. All 20 cases were managed with hemiarthroplasty with bipolarprosthesis. The following observations were made from the data collected during the study.

Table 1: Age distribution of patients.

\begin{tabular}{|lll|}
\hline Age in years & No. of patients & $\%$ \\
\hline $\mathbf{6 0 - 6 9}$ & 8 & 40.0 \\
\hline $\mathbf{7 0 - 7 9}$ & 6 & 30.0 \\
\hline $\mathbf{8 0 - 9 0}$ & 6 & 30.0 \\
\hline Total & 20 & 100.0 \\
\hline
\end{tabular}

Table 2: Gardens type distribution of patients.

\begin{tabular}{|lll|}
\hline Gardens type & No. of patients & $\%$ \\
\hline Type 3 & 3 & 15.0 \\
\hline Type 4 & 17 & 85.0 \\
\hline Total & 20 & 100.0 \\
\hline
\end{tabular}

Table 3: Pain distribution of patients.

\begin{tabular}{|lll|}
\hline Pain & No. of patients & $\%$ \\
\hline None & 6 & 30.0 \\
\hline Mild & 1 & 5.0 \\
\hline Slight & 13 & 65.0 \\
\hline Total & 20 & 100.0 \\
\hline
\end{tabular}

In our study among 20 cases most of the patients were in the age group of 60-70 years of age with mean age group is $72.30 \pm 8.93$ years. Females were more common $65 \%$ than male patients in which 13 patients were female and 7 patients were male. Left sided fracture were predominant $75 \%$ with 15 cases fracture was on the left side and 5 cases were on the right side.
Table 4: Use of stairs distribution of patients.

\begin{tabular}{|lll|}
\hline Stairs & No. of patients & $\%$ \\
\hline No & 1 & 5.0 \\
\hline In any manner & 1 & 5.0 \\
\hline Unable & 2 & 10.0 \\
\hline Using a railing & 10 & 50.0 \\
\hline Without a railing & 6 & 30.0 \\
\hline Total & 20 & 100.0 \\
\hline
\end{tabular}

Trivial trauma was most common mode of injury of about $85 \%$ and $15 \%$ of the patients met with road traffic accident.

In our study, 17 cases had type 4 fracture neck of femur according to gardens classification making $85 \%$ of the patients. Postoperatively $60 \%$ of the patients stayed in hospital till day 11-15 with mean post operative duration was 13.00 days. Postoperatively $50 \%$ of the patients were mobilised on postoperative day 2 and $30 \%$ of the patients were mobilised on post operative day 3 . In this study $40 \%$ of the prosthesis were of size 43 with mean \pm SD: $44.90 \pm 3.58$.

Table 5: Results of Harris hip score $(n=20)$.

\begin{tabular}{|lll|}
\hline Result & No. of patients & $\%$ \\
\hline Excellent & 7 & 35.0 \\
\hline Good & 8 & 40.0 \\
\hline Fair & 2 & 10.0 \\
\hline Poor & 1 & 5.0 \\
\hline Failure & 2 & 10.0 \\
\hline Expired & 0 & 0.0 \\
\hline Total & 20 & 100.0 \\
\hline
\end{tabular}

\section{Assessment of functional result}

In this study, 20 patients with fracture neck of femur underwent hemiarthroplasty with bipolar prosthesis were assessed using Harris hip score. Patients were followed up on $6^{\text {th }}, 12^{\text {th }}, 18^{\text {th }}, 24^{\text {th }}$ week. The results of the final follow up, that is 6 months was considered for our analysis. Assessment was done with the pain, limp, use of support, walking distance, climbing of stairs, put on shoes and socks, sitting in chair, enter public transportation, deformities, leg length discrepancy and range of motion

The patients were enquired about the kind of pain experience by them during their daily routine activities and recorded according to the Harris hip score. $65 \%$ of the patient had slight pain during their daily activity and $30 \%$ had no pain. $55 \%$ of the patients had slight limp at end of final follow-up and $30 \%$ patients had no limp. $50 \%$ of the patients had no need of support while walking and $50 \%$ of the patients needed support for walking. All the patients in the study were enquired about the distance that they were able to walk and graded. $35 \%$ of the were able to walk unlimited $20 \%$ patients were able to walk indoors only. All patients were enquired about the duration of ability to sit on a chair $90 \%$ of the patients were comfortable to sit on a chair for more than an hour in a chair. 

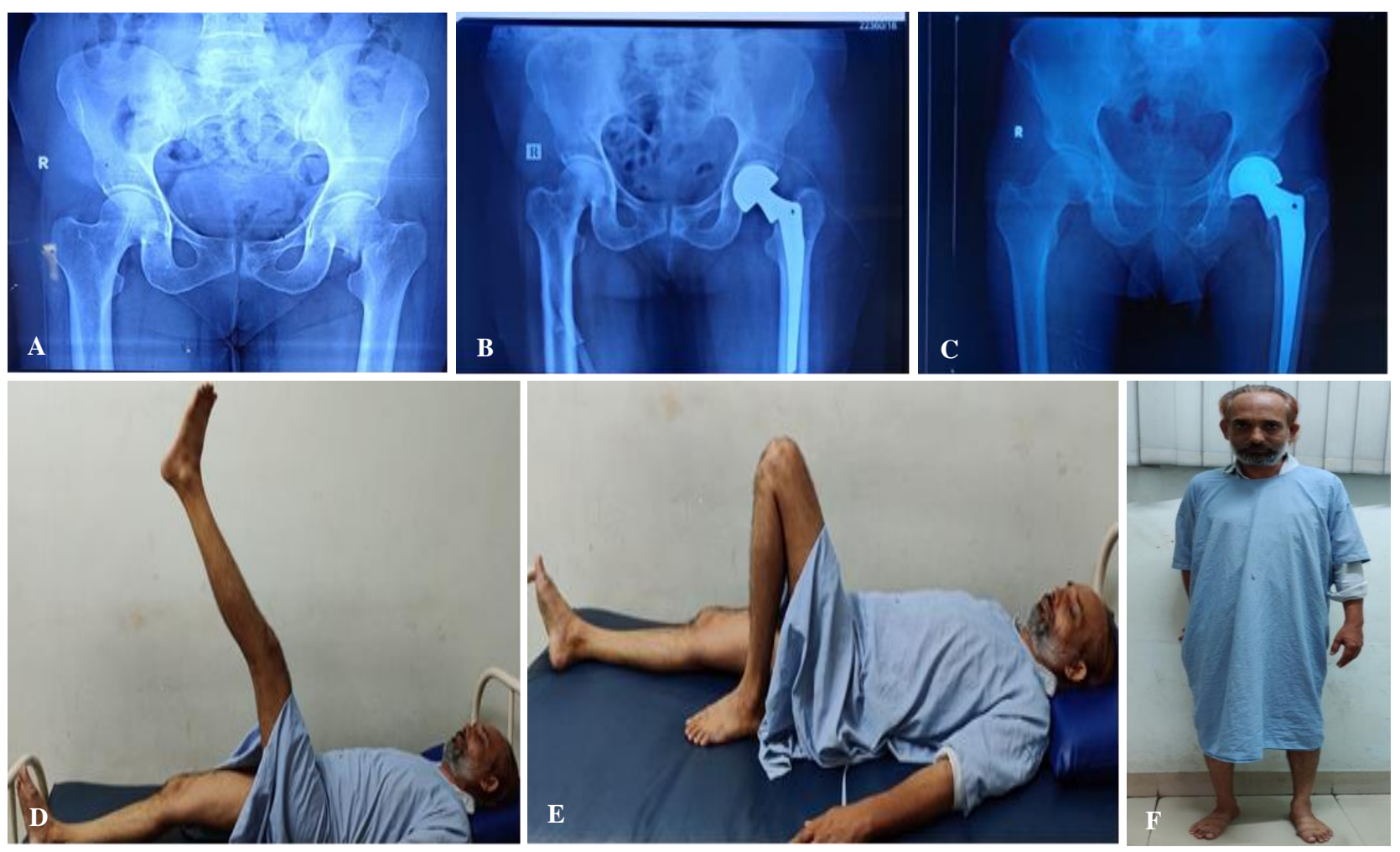

Figure 1: Radiological photos of case no 6. (A-C) Pre op post op 24 week, (D-F) clinical picture at 24 weeks.

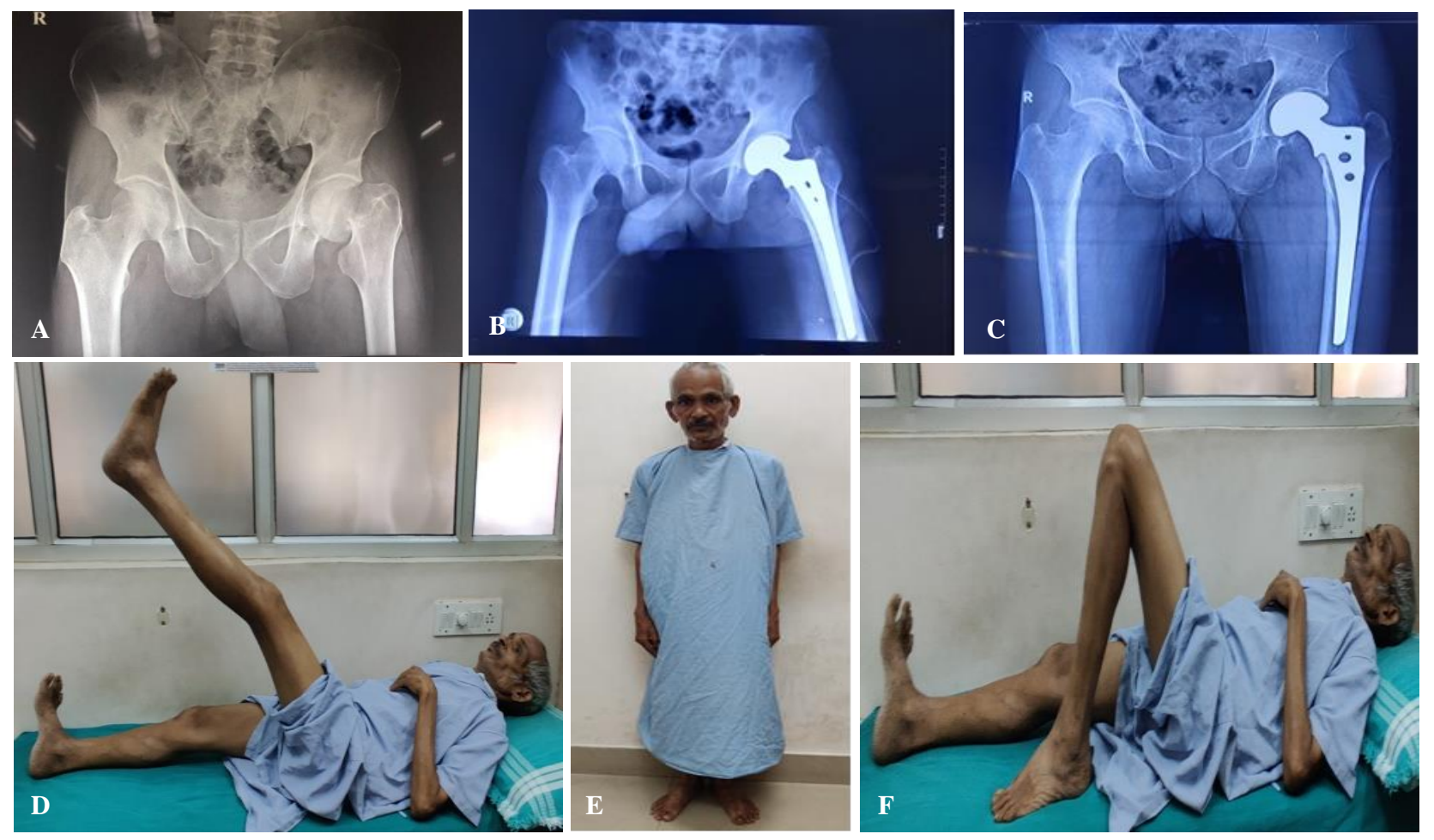

Figure 2: Radiological photos of case no 9. (A-C) Preop post op final followup, (D-F) clinical picture at 24 weeks.

In our study, out of all patients $50 \%$ of the patients were able to climb stairs with support of a railing and $30 \%$ of patients able to climb stairs without support and rest were unable to climb stairs. In our study, $70 \%$ of the patients were able to use public transport and remaining $30 \%$ of patients did not use public transport. In our study, out of all patients $65 \%$ of the patients were able to wear shoes with difficulty. In our study, patients were assessed for deformity at the end of 24 weeks. Only one patient had fixed external rotation deformity. 

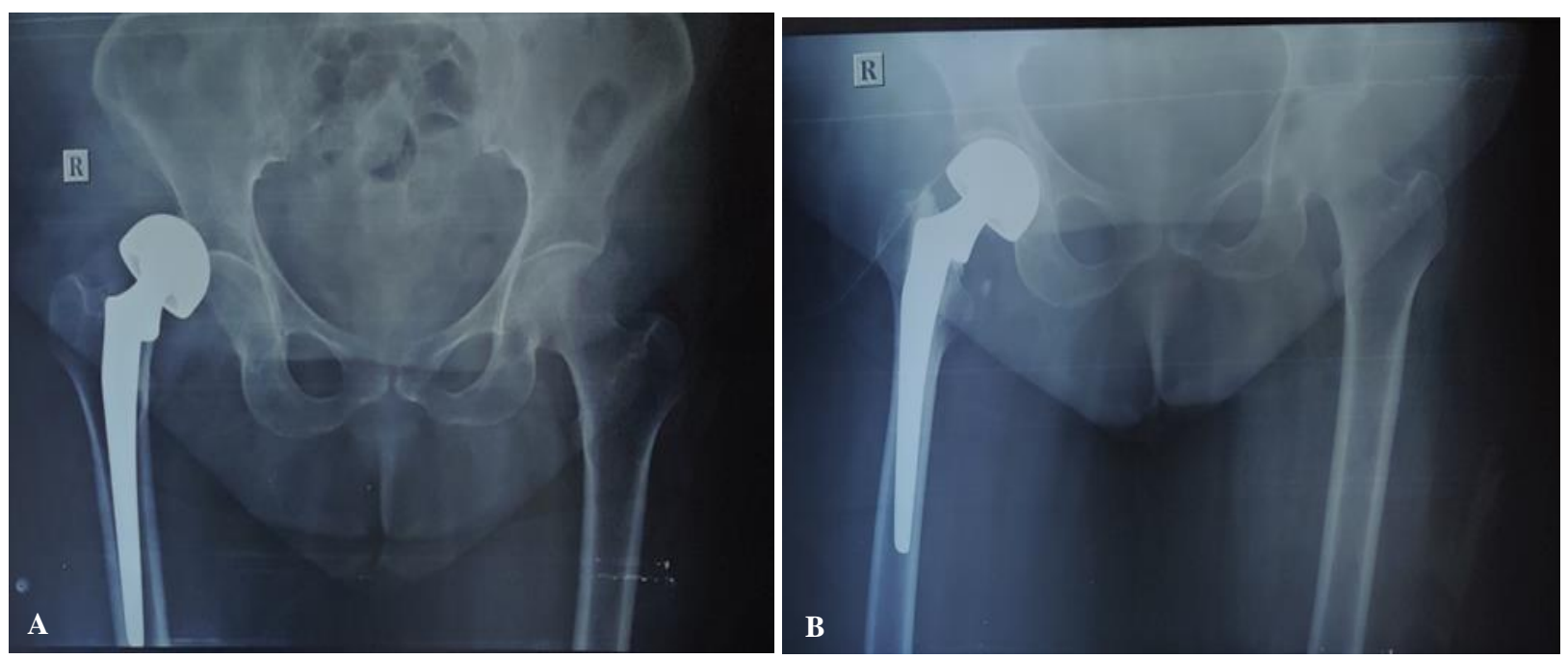

Figure 3: Complication (A) pre operative (B) post operative.

In our study, cumulative range of movements was assessed. $15 \%$ of the patients had ROM in range of less than $210^{\circ}$ and $85 \%$ of patients had ROM in range $211-300^{\circ}$. In our study, $35 \%$ of the patients had HHS score in range of $91-100$ and $35 \%$ in $81-90$ range. In our study, $5 \%$ of the patient had dislocation of the prosthesis and $10 \%$ of the patients had superficial wound infection.

In our study, $35 \%$ and $40 \%$ of the patients have excellent and good outcome respectively.10\% of the patients had fair results and $5 \%$ had poor results.

\section{DISCUSSION}

Out of 30 patients, the average age of the patients in our study was 72.30 years of age. The average age group is 6070 years. Female preponderance noted in our study. $65 \%$ of the patients were female. Elderly female is prone to fracture neck of femur due to osteoporosis.

Similar results were reported by other author with female preponderance. In our study, out of 20 patients fracture neck of femur as common on left side compared to right side. $75 \%$ of the patients had fracture on left side. Similar results were reported in Boyd et al reported 55\%. ${ }^{3}$ All fracture belonged to displaced fracture according to garden classification type 3 and 4 . In Kulkarni et al $82 \%$ of his patients belonged to type 3 and 4 gardens classification. ${ }^{4}$ Mukherjee et al had $85 \% .^{20}$

In our series, the nature of injury was $85 \%$ of the patients had met with trivial trauma and $15 \%$ of the patients met with road traffic accidents. Similarly, in other studies Solomon (1968), Evarts, Ingalhalikar et al, Seth believe that the intracapsular fracture are stress fractures through pathological bone secondary to osteoporosis or osteomalacia. ${ }^{5-7}$
In our study, all patients were discharged once they were fit and after active mobilisation with walker support. $60 \%$ of the patients were discharged $11-15$ days of hospitalisation.

Most of the patients in our hospital come from rural region with financial difficulties and lack of transportation were main reasons for delay. The interval of surgery to mobilisation $50 \%$ of the patients were mobilised on postoperative day 2 and $30 \%$ of the patients were mobilised on day 3 .

\section{Complication}

\section{Dislocation of the prosthesis}

Among 20 cases 1 patient had posterior dislocation of the prosthesis on postoperative day 12. An attempt of closed reduction under GA was attempted but were unable to reduce. Patient as taken for revision surgery as done with bipolar prosthesis and immobilised for 6 weeks and later mobilised. The cause for dislocation was malalignment of the prosthesis.

The rate of dislocation can be minimized with repair of the posterior capsule and posterior soft tissue. Proper placement of the implants is of the utmost importance to minimize complications. Other contributing factors that lead to dislocation are implant malpositioning and patient factors. ${ }^{8}$

Incidence of dislocation of prosthesis ranging from $1.1 \%$ at one year follow-up to $5 \%$ at 20 years.

Madanat et al found that a smaller centre edge angle (CEA) and decreased femoral offset (FO) resulted in higher dislocation rates. ${ }^{9}$ 
Table 6: Comparison of Harris hip score with other series.

\begin{tabular}{|lllllll|} 
Result & Score & $\begin{array}{l}\text { Our study } \\
(\boldsymbol{\%})\end{array}$ & $\begin{array}{l}\text { Sherwani et al } \\
(\boldsymbol{\%})\end{array}$ & $\begin{array}{l}\text { Lestrange }^{\mathbf{1 8}} \\
(\boldsymbol{\%})\end{array}$ & $\begin{array}{l}\text { Gilberty }^{\mathbf{1 9}} \\
(\boldsymbol{\%})\end{array}$ & $\begin{array}{l}\text { Mukherjee et al }^{\mathbf{2 0}} \\
(\boldsymbol{\%})\end{array}$ \\
\hline Excellent & $91-100$ & 35 & 31 & 39.6 & 64 & 29 \\
\hline Good & $80-89$ & 40 & 46 & 31.2 & 28 & 49 \\
\hline Fair & $70-79$ & 10 & 15 & 15.3 & - & 18 \\
\hline Poor & $<70$ & 5 & 8 & 13.9 & 0.8 & 4 \\
\hline Average & & 82.3 & 82 & 82.6 & & \\
\hline
\end{tabular}

Ninh et al study, they also found a shorter residual femoral neck to be significant (13 mm versus $16 \mathrm{~mm}, \mathrm{p}=0.029) .{ }^{10}$

In our study, we had 2 cases of superficial infection. It was managed conservatively with antibiotics, based on the culture growth. Reported incidences of superficial infection after primary prosthetic arthroplasty include Salvatti et al 8.3\%, Saraf et al 3.7\%, Mukherjee et al 3\%, Bavadekar et al 7.6\%.11,14,20

In our study, $60 \%$ of the patients had slight pain which did not interfere with their daily activities and $30 \%$ of the patients had no pain. $95 \%$ of the patients had none to slight pain compared to other studies Sherwani et al $88 \%$, Labelle et al $79.2 \%{ }^{16,17}$

In our study $50 \%$ of the patients did not need any support while walking and $20 \%$ of the patients need a cane to walk. Saraf et al reported $52.7 \%$ patients using cane regularly, $23.1 \%$ occasionally and $21.8 \%$ were not using it. ${ }^{14}$ In our study, $85 \%$ of the patients had ROM more than $210^{\circ}$. Cornell et al who reported that patients with bipolar prosthesis did better on walk tests and had better range of motion at 6 months. ${ }^{15}$ Radiological assessment in present study, there as one case of dislocation of prosthesis. There was no incidence of heterotrophic ossification, femoral loosening, acetabular erosion, protrusion.

All the cases in our series were assessed according to Harris hip score and graded accordingly as excellent, good, fair, poor and failure. We got average score of $82.3 \%$ as compared to other studies Cadler et al $72 \%$, Nottage $85 \% .^{20}$ At the end 6 months, $35 \%$ of the patients had excellent score, $40 \%$ of the patients had good score and $10 \%$ had fair result as shown and compared in Table 6.

\section{CONCLUSION}

In our present study, 20 cases with fracture neck of femur studied. Al patients underwent hemiarthroplasty with bipolar prosthesis. The clinical data was assessed, analysed evaluated and following conclusion were made.

Fracture neck of femur is common in elderly population. Increased incidence of fracture neck of femur is due to osteoporosis and other medical comorbidities.

Increased risk of fracture neck of femur is noted following trivial trauma. Increased female preponderance is noted and most cases were left sided. Bipolar hemiarthroplasty can be performed safely in elderly population yielding satisfactory results. Early mobilisation, pain free hip and with good level of activity is obtained following bipolar hemiarthroplasty

We conclude that functional outcome following bipolar hemiarthroplasty is good, thus bipolar hemiarthroplasty is ideal treatment for fracture neck of femur in elderly.

\section{ACKNOWLEDGEMENTS}

It is an immense pleasure to present before you this paper and we thank our colleagues from Kempegowda Institute of Medical Sciences who greatly assisted in this research. We thank head of the department and faculty of Department of Orthopaedics of Kempegowda Institute of Medical Sciences whose inputs greatly improved this research.

\section{Funding: No funding sources}

Conflict of interest: None declared

Ethical approval: The study was approved by the institutional ethics committee

\section{REFERENCES}

1. Thorngren KG, Hommel A, Norrman PO, Thorngren $\mathrm{J}$, Wingstrand $\mathrm{H}$. Epidemiology of femoral neck fractures. Injury. 2002;33(Suppl 3):C1-7.

2. Koval KJ, Zuckerman JD. Hip Fractures: I. Overview and Evaluation and Treatment of Femoral-Neck Fractures. J Am Acad Orthop Surg. 1994;2(3):141-9.

3. Boyd HB, Salvatore JE. Acute fractures of the femoral neck: Internal fixation or Prosthesis? JBJS 1964;46:1066-8.

4. Kulkarni GS. Pathology of fracture neck of the femur. Clin Orthop India. 1987;1;92-6.

5. Evarts CM. Endoprosthesis as the primary treatment of femoral neck fractures. Clin Orthop. 1973;92:6976.

6. Ingalhalikar VT, Kumta S. Fracture neck femur anatomical and biomechanical aspects. Clin Orthop India. 1987.

7. Seth MK. Stress fractures of the neck of femur. Clin Orthrop India. 1987;1:105-9.

8. Rodriguez-Buitrago A, Attum B, Cereijo C, Yusi K, Jahangir AA, Obremskey WT. Hemiarthroplasty for Femoral Neck Fracture. JBJS Essential Surgical Techniques. 2019;9(2):13. 
9. Madanat R, Mäkinen TJ, Ovaska MT, Soiva M, Vahlberg T, Haapala J. Dislocation of hip hemiarthroplasty following posterolateral surgical approach: A nested case-control study. Int Orthop. 2012;36(5):935-40.

10. Ninh CC, Sethi A, Hatahet M, Les C, Morandi M, Vaidya R. Hip dislocation after modular unipolar hemiarthroplasty. J Arthroplasty. 2009;24(5):768-74.

11. Salvatti EA, Wilson PO. Long term results of femoral head replacements JBJS. 1972;54:1355-6.

12. Bavadekar AV, Manelkar KR. Hemiarthroplasty of the hip in the treatment of intracapsular fracture neck of the femur state of the art and an appraisal. Clin Orthop India. 1987;1:43-52

13. La Belle, Colwill JC. Bateman bipolar hip arthroplasty for fracture neck of femur, a five to ten year of study", Swanson AB Clinorthop. 1990;251:20.

14. Saxena PS, Saraf JK. Moore Prosthesis in fracture neck of femur. Indian J Orthop. 1978;12:138-45.

15. Cornell CN, Levine D, O'Doherty J, Lyden J. Unipolar Versus bipolar hemiarthroplasty for the treatment of femoral neckfractures in the elderly. Clin Orthop Relat Res. 1998;348:67-71.
16. Calder SJ, Anderson GH, Jagger C, Harper WM, Gregg PJ. Unipolar or bipolar prosthesis for displaced intracapsular hip fracture in octogenarians:a randomised prospective study J Bone Joint Surg Br. 1996;78:391-4.

17. Sherwani MK, Asif N. Bipolar hemiarthroplasty of the hip - a reviw of 80 cases, Indian J Orthop. 1999;33:23-5.

18. Lestrange NR. Bipolar arthroplasty for 496 hip fracture. CORR. 1990;251:07-19.

19. Gilberty RP, Hemiarthroplasty of the hip using lo fricition bipolar endoprosthesis. Clin Orthop. 1983;175;86-92.

20. Mukherjee DL, Puri HC. Early hemiarthroplasty for fresh fractures of the neck of the femur in geriatric patients. Indian Journal of Surgery. 1986;48:77-80.

Cite this article as: Mallegowda RA, Seetharam CT, Sundaram S, Siddegowda JB, Nijalingappa V. Prospective study of the functional outcome of uncemented bipolar hemiarhroplasty in displaced fracture neck of femur in elderly. Int J Res Orthop 2020;6:567-73. 